\title{
Chinese ESL Learners' Perceptions of English Language Teaching and Learning in Australia
}

\author{
Jie Fan $^{1}$ \\ ${ }^{1}$ Department of Linguistics, Faculty of Human Sciences, Macquarie University, Sydney, Australia \\ Correspondence: Jie Fan, Department of Linguistics, Faculty of Human Sciences, Macquarie University, Sydney, \\ Australia.
}

Received: May 13, 2019 Accepted: June 18, 2019 Online Published: June 20, 2019

doi: 10.5539/elt.v12n7p139 URL: https://doi.org/10.5539/elt.v12n7p139

\begin{abstract}
In recent decades, with the rapid economic development of China, there has been a large influx of Chinese students into Western countries to pursue their studies. Empirical research reveal that some students encounter linguistic and academic challenges, and find it difficult to adapt to the Western learning environment. Adopting a qualitative approach, this research examines how Chinese ESL learners perceive English language teaching in Australia and the learning difficulties they face. By doing so, it seeks to help instructors make informed pedagogical decisions and assist learners in addressing these difficulties. Ten Chinese students who were or have been enrolled in a university English language program participated in interviews. The findings reveal that the participants show highly positive attitudes toward the communicative approach, and mostly favor grammar instruction within communicative practice. The learning difficulties they experience are mostly influenced by their prior exposure to Chinese teaching and learning styles. The study suggests that teachers should be aware of learners' needs and prior learning experiences, so that they could engage in more effective interventions, and assist learners in developing their own learning strategies in the academic adaptation.
\end{abstract}

Keywords: Chinese ESL learners, learner perceptions, language teaching and learning

\section{Introduction}

In recent decades, with the rapid economic development of China, there has been a large influx of Chinese students into Western countries to pursue their studies, particularly English-speaking countries such as the United States, the United Kingdom, Canada, Australia and New Zealand (Yu \& Shen, 2006). Statistics show that China by far remains the world's largest source country of international students, and plays an important strategic role in the international education market (Chinese Ministry of Education, 2018). The Sydney Morning Herald (Koziol, 2018) reported that at the end of 2017, Chinese students accounted for $43.3 \%$ of the total international student cohort in Australia. While international students have brought financial inflows and cultural diversity to Australian university communities, some encounter linguistic and academic challenges, and find it difficult to adapt to the Western learning environment (Ashton-Hay et al., 2016; Floyd, 2015). Because students' learning experiences in their home country are likely to influence their learning in the host country, it is necessary to "discover their feelings and beliefs about language learning experiences" (Barkhuizen, 1998, p. 86) and understand their needs and expectations in the host society. This may help educators to adopt better approaches and plan appropriate language instruction that is geared to learners' needs and interests. Furthermore, Chinese students have been stereotyped as "rote-learners" and "passive listeners" in most of the previous studies (Atkinson, 1997; Gu \& Maley, 2008). This research intends to contribute to the general understanding of Chinese ESL learners' perceptions, and of the roles they would like to adopt.

\section{Literature Review}

\subsection{Perception}

It is very important to operationalize the concept "perception" and identify its key indicators, because it is closely connected to the research topic. In the literature, perception has been viewed and considered from different perspectives. From a biological or physiological viewpoint, Smith (2002) concludes that perception involves stimulation provoked by stimuli in the human organs through the five senses of vision, hearing, smell, touch, and taste. In other words, it comprises the formation and establishment of human views and impressions 
of the external world (Grundmeyer, 2012). Similarly, Wolfe, Kluender and Dennis (2009) consider perception to be a physical impression that arises from a person's prior knowledge, idea, or inner sense.

From a cognitive or psychological perspective, Panksepp (1998) views perception as a mental process whereby hypotheses concerning future happenings work together with the information that comes from people's memories, contributing to the formation and interpretation of representation. In this way, human perception can be understood as an interpretation of a representation of the world around us.

Merleau-Ponty (2002) takes a different approach, understanding the concept of perception as a domain related to subjectivity and historicity, and as an amalgam of affective experiences such as love and hate, tensions, contradictions, and dialogue.

Based on the above review, human perceptions can be generalized as impressions, interpretations of representations, and affective experiences. Accordingly, the interview questions that seek to reveal students' perceptions of ELT in Australia are categorized into three types (see Appendix B): perceptions in relation to the students' impressions; perceptions in relation to their interpretations of representations; and perceptions in relation to their affective experiences.

\subsection{Studies on English Language Learners' Perceptions of Communicative Language Teaching (CLT) and Grammar Translation Method (GTM)}

The literature mostly offers comparative studies of learner beliefs about CLT and GTM among students in various cultural and linguistic environments, such as Barkhuizen (1998); Durrani (2016); Ikpia (2001); Incecay and Incecay (2009); Kavoshian, Medadian and Lorzadeh (2013). According to the findings, learners' perceptions differ across cultural groups, and are dependent on the ethnic and situational factors. On the other hand, other studies have sought to examine the variety and uniformity of intra-cultural group's perceptions of grammar instruction. For example, by discovering differences in belief in relation to grammar learning between two groups of Korean students, Horwitz (1999) concluded that the intra-cultural group variation in learner beliefs may be related to individual learner characteristics, such as age, stage of life, language-learning context, and specific classroom practices.

Despite these findings, Horwitz (1999) has not further investigated how language learners' perceptions change with their learning environment and learning experience. Saito and Ebsworth (2004), by using a mixed research method, examined the variance in beliefs between college-level Japanese ESL and EFL learners. The findings revealed that learners' perceptions differed with respect to their language teachers and classroom activities in the two teaching contexts. Compared with EFL learners, ESL learners showed more positive attitudes toward classroom participation, learner-centered approach, and physical proximity to teachers. Although the two groups were similar in their views of instrumental motivation, they differed with regard to this factor; more ESL learners learned English for the purposes of furthering education or work, while many EFL learners simply aimed to fulfil university requirements. It can be inferred that these differences reflected in the cross-sectional study are possibly attributable to the completely different teaching contexts and instructional practices, as well as the learners' motivations to learn English. Similarly, in another study conducted among 32 Korean ESL learners in the US, Mitsui (2009) examined the effect of overseas learning experiences on language learning. The results demonstrated that the participants were interested in learning English using visual, aural, and kinesthetic methods, and showed positive attitudes toward communicative activities such as oral presentations and group work. However, given the students' familiarity with traditional teaching methods and the influence of Confucianism, the researcher recommended adapting CLT to Korean contexts. As can be seen from the above studies, overseas learning experiences exert a strong influence on the perceptions and socio-cultural values of learners, in particular of East Asian students, who universally fall under the umbrella of Confucianism.

\subsection{Studies on Language Learners' Perceptions of Grammar Instruction in Communicative Activities}

Early studies tended to focus on the CLT method in meaningful contexts, but overlooked its connections with grammar (Krashen \& Terrell, 1983). In recent decades, SLA researchers have examined the role of grammar instruction in the growth of language awareness and development (Schmidt, 1995), and explored its possibilities in communicative activities. For example, Imai (2007) used a questionnaire to examine the beliefs of 166 Japanese high-school students regarding two types of grammar instruction - isolated and integrated form-focused instruction (FFI) - in a content-based ESL program in the US. According to the findings, learners showed preference for integrated FFI, and L2 proficiency was the major contributor to the differences in learner beliefs. Similarly, Zeng (2004) investigated the role of grammar instruction in communicative activities among 15 Chinese ESL students and four Canadian teachers in a Canadian language center. The results showed that learners viewed grammar instruction within CLT as an effective approach that helped them to realize the function of grammar and achieve 
communicative competence. In the light of these findings, Zeng (2004) suggested combining explicit and implicit grammar knowledge in communicative and meaningful contexts.

Based on the above inter-cultural and intra-cultural comparative studies, learners' perceptions about CLT and GTM are generally context-specific. Individual characteristics such as age, ethnic/cultural/linguistic background, L2 proficiency, and learning aptitude may account for the complexity and dynamics of learner beliefs and influence learners' preferences for particular types of teaching pedagogies (Horwitz, 1999).

\subsection{Studies on Language Learning Difficulties Experienced by International Students}

With the increasing number of international students in English-speaking countries, their language difficulties arising from the insufficient L2 proficiency have raised much concern, with specific issues reported in the literature including problems with academic writing, oral communication, group participation, and the comprehension of lectures (Robertson et al., 2000; Khawaja \& Stallman, 2011; Zhang \& Mi, 2010).

For example, Robertson et al. (2000) investigated the difficulties experienced by international students at one Australian university. According to the survey results, the issues raised mainly include difficulties in understanding colloquial language, writing reports, and making presentations. Difficulty in taking responsibility for individual learning was regarded as a primary concern. In another qualitative study conducted among 22 international students from another Australian university, Khawaja and Stallman (2011) discovered that the main issue experienced by most L2 tertiary students was understanding the Australian accent. Research conducted by Wong (2004) shed light on the issue, as he found that language difficulties experienced by Asian international students were attributed to their prior exposure to different teaching and learning styles. According to the findings, some Asian students are accustomed to the cramming method of teaching, and find it difficult to explore knowledge by themselves and work on assignments independently.

Hence, as reflected in the literature, language limitations and prior teaching and learning styles are associated with students' language difficulties. To some extent, these difficulties can impact on the learners' ability to cope with academic demands in Western contexts and make a smooth transition to a new academic environment (Lee, Farruggia, \& Brown, 2013)

Generally, a review of the literature reveals that particular cultures of learning and contextual factors significantly affect English instructional practices. Learners evince varied beliefs and attitudes about the CLT and GTM as a result of individual differences in language proficiency and social contexts. Although comparative studies of learner beliefs about these two teaching methods have been conducted in various cultural and linguistic environments, there has been little research into what Chinese ESL learners feel about Western teaching methods, and how their perceptions change as a result of their learning experiences and teaching contexts. In spite of the identification of a range of language difficulties experienced by L2 learners in English-speaking countries, there is no empirical research that focuses specifically on Chinese students.

In addition, it should be noted that many Chinese students are changing and developing their attitudes in response to socio-economic changes, a fresh insight into the paradox of Chinese learners is highly needed. Further research is required to identify how the dynamics of cultural change and situated contexts influence their perceptions of teaching and learning, as well as their role as learners.

\section{Research Questions}

This study aims to investigate how Chinese ESL learners perceive English language teaching and learning in Australian contexts, and what learning difficulties they may face in their English studies. This would have great significance for pedagogical decision making and the formulation of learning strategies. To this end, the following research questions are formulated for the study:

1) What are Chinese ESL learners' perceptions of English language teaching and learning in Australia?

2) What are Chinese learners' perceived English learning difficulties in Australia?

\section{Methodology}

\subsection{Research Participants}

Ten Chinese students who were or are currently enrolled at Macquarie University English Language Center (ELC) were recruited through campus advertisement and snowball sampling. These students were between 18 to 30 years of age. Eight of them have completed more than one 15-week course at the ELC and are currently engaged in master's programs at Macquarie University. Two are still enrolled in the English courses. The IELTS scores of the participants range from 4.5 to 7 . These individual differences indicate that they may have varied educational backgrounds and English language proficiency. The table below shows the participants' demographic information. 
Table 1. Participants' demographic information

\begin{tabular}{|c|c|c|c|c|c|c|c|}
\hline Pseudonym & Gender & Age & $\begin{array}{c}\text { Highest } \\
\text { degree } \\
\text { completed }\end{array}$ & $\begin{array}{l}\text { Degree applying } \\
\text { for or majoring in }\end{array}$ & $\begin{array}{l}\text { IELTS test } \\
\text { score }\end{array}$ & $\begin{array}{l}\text { Study period } \\
\text { at ELC }\end{array}$ & $\begin{array}{c}\text { Residency } \\
\text { status in } \\
\text { Australia } \\
\text { (in months) }\end{array}$ \\
\hline Alicia & $\mathrm{F}$ & 28 & Bachelor & $\begin{array}{c}\text { Master of } \\
\text { accounting }\end{array}$ & 6 & 20 weeks & 12 \\
\hline Betty & $\mathrm{F}$ & 24 & Bachelor & $\begin{array}{l}\text { Master of } \\
\text { international } \\
\text { business }\end{array}$ & 5.5 & 22 weeks & 12 \\
\hline Cassy & $\mathrm{F}$ & 23 & Bachelor & $\begin{array}{c}\text { Master of } \\
\text { accounting }\end{array}$ & 6 & 20 & 12 \\
\hline Chan & $\mathrm{F}$ & 24 & Bachelor & $\begin{array}{c}\text { Master of } \\
\text { accounting }\end{array}$ & 5.5 & 25 & 8 \\
\hline Danna & $\mathrm{F}$ & 25 & Bachelor & $\begin{array}{l}\text { Master of } \\
\text { international } \\
\text { business }\end{array}$ & 5.5 & 25 & 12 \\
\hline Janice & $\mathrm{F}$ & 23 & Bachelor & $\begin{array}{l}\text { Master of } \\
\text { international } \\
\text { business }\end{array}$ & 6.5 & 15 & 12 \\
\hline Lily & $\mathrm{F}$ & 19 & High school & $\begin{array}{l}\text { Bachelor of } \\
\text { management }\end{array}$ & 4.5 & 20 & 5 \\
\hline Monica & $\mathrm{F}$ & 24 & Bachelor & $\begin{array}{l}\text { Master of applied } \\
\text { linguistics }\end{array}$ & 7 & 15 & 15 \\
\hline Peggy & $\mathrm{F}$ & 23 & Bachelor & $\begin{array}{l}\text { Master of } \\
\text { commerce }\end{array}$ & 6.5 & 15 & 12 \\
\hline Ying & $\mathrm{F}$ & 18 & High school & $\begin{array}{l}\text { Bachelor of } \\
\text { commerce }\end{array}$ & 5.5 & 15 & 6 \\
\hline
\end{tabular}

Note. Pseudonyms are used for participants' names.

\subsection{Data collection}

The data was collected through semi-structured private interviews to gain an in-depth understanding of learners' perceptions. The interviews comprise two sections. Appendix A contains the participants' personal information. Appendix B includes two parts: learners' perceptions of ELT in Australia, and their learning difficulties. In terms of learners' perceptions, as illustrated previously, for the purposes of operationalizing the concept of "perception", three specific indicators were identified based on the literature review: impressions, interpretations of representations, and affective experiences. Accordingly, the interview questions were categorized into three types (see Appendix B, part 1): perceptions relating to the students' impressions, perceptions relating to the students' interpretation of the representations, and perceptions relating to their affective experiences.

The interviews were conducted in Chinese so that the students could fully express their ideas without worrying about their English. After all the interviews were audio-recorded and transcribed, a copy of the transcript was sent to each participant for verification. Finally, the transcripts were translated into English for analysis.

\subsection{Data Analysis}

The interview data was analyzed using an inductive (bottom-up) approach. In this way, patterns and themes gradually emerged from the data. This framework yielded useful concepts and suggested directions along which to look for potential coding categories. Simultaneously, a deductive approach was employed by first revisiting the relevant literature as a preliminary guide and then exploring the categories that were identified as salient to the topic (Rossman \& Rallis, 2003). 


\section{Results and Discussions}

After data analysis and interpretation, the order and structure, as well as meanings, became more salient. Two major themes corresponding to the two research questions were determined, respectively Chinese learners' perceptions and learning difficulties. Three salient sub-themes with regard to the learners' perceptions also emerged: comparison between learning experiences in China and Australia, attitudes toward communicative activities, and attitudes toward grammar activities. Under each sub-theme, the categories and evidence identified in the transcripts were then sorted and listed. The same procedure was followed for the theme of learning difficulties. The table below summarizes the themes, sub-themes, and categories.

Table 2. Findings of major themes, sub-themes and categories

\section{Chinese learners' perceptions}

1) Comparison between learning experiences in China and Australia

- Learning aims

- Learning environment

- Teacher/learner roles

- Teaching and learning activities

- Assessment

- Connections between the two learning experiences

2) Chinese learners' attitudes toward CLT

- Attitudes toward communicative activities

3) Chinese learners' attitudes toward grammar activities

- A preference for grammar learning through games

- A preference for grammar learning in other modalities

- Less interest in learning grammar

- A lack of interest in learning grammar

\section{Chinese learners' learning difficulties}

1) Difficulties in academic writing

2) Difficulties in communication

3) Difficulties in independent learning

5.1 Question 1 What Are Chinese ESL Learners' Perceptions of English Language Teaching and Learning in Australia?

\subsubsection{Comparison Between Learning Experiences in China and Australia}

\section{1) Learning aims}

The results revealed that learners generally felt that there were different learning aims in the two settings. As a result of the exam-oriented educational system in China, most of them felt compelled to learn English, and perceived that passing exams was the ultimate goals of learning English. Conversely, they thought that the reason behind learning English in Australia was to develop students' abilities to use English, rather than to deal with exams. Below are Peggy and Danna's comments.

\section{Excerpt 1}

I learned English in China to pass university entrance exams, the College English Test Band 4... I was instructed and practiced based on the exam requirements. Although students can be trained to achieve satisfactory scores, their communication skills, may not reach a high level. (Peggy).

Excerpt 2

In Australia, teaching and learning emphasize learner autonomy and promote communicative approach. English instruction is aimed at comprehensively developing students' English competency, and in particular their 


\section{communication skills (Danna).}

The extracts revealed that most participants held positive attitudes about how English was taught in Australia. They considered that English teaching and learning should be aimed at language use, rather than exam success, and that an exam-oriented educational system was not conducive to the development of their communicative competence.

\section{2) Learning environment}

The results indicated that the participants generally had favorable impressions about the learning environment at the ELC. For example, six out of ten learners described the learning atmosphere as "open and lively", and two said "relaxed but not sloppy".

Additionally, some learners found that the small classes at the ELC were very helpful in creating a cooperative and communicative environment for discussions and interactions. Six participants agreed that " $a$ lot of communication takes place between teachers and learners" and expressed that they were happy with the "equal student-teacher relationship".

\section{3) Teacher/learner roles}

The results suggested that the participants believed that the roles of teachers and learners were entirely different in the two teaching contexts. They reported that in Chinese classrooms, teachers are usually perceived as authorities or transmitters of knowledge, and students are deemed to be passive knowledge receptors, while in Australian classrooms, teachers tend to assume the roles of facilitators, providing scaffolding and support to their students. Learners are expected to be active participants, taking on a higher degree of responsibility for their own learning. Monica compared the teacher/learner roles in the two settings:

\section{Excerpt 3}

Teachers are considered to be authority figures in China. Students seldom challenge them in the classroom, and view their opinions as most accurate and reliable. While in Australia, learners are mobilized to participate in the classroom activities and freely voice their opinions. Teachers encourage brainstorming and discussions instead.

When asked whether they preferred passively receiving knowledge or actively participating in classroom activities, participants' responses varied. Six out of ten said that they enjoyed being active participants, while the remainder thought that the choice about whether to be an active participant or a passive recipient needs to be based on specific conditions.

Given her Chinese educational and linguistic background, Monica was aware of Chinese students' specific needs and characteristics. She commented:

\section{Excerpt 4}

Whether to choose to be an active participant or passive learner really depends. Everyone has different English levels and learning needs, so it's very hard to seek unity in learning styles. I once observed a classroom as a student-teacher in China, and found that some students could speak English fluently, while others struggled to produce sentences. So, not everyone can be an active participant in the classroom.

This suggests that the contextual factors and learners' needs, as well as individual differences in proficiency, may need to be taken into account, when applying a learner-centered approach.

Despite that, the majority of participants perceived and interpreted their role as classroom participants, rather than the "obedient passive listeners" described in most of the prior studies. Hu (2002) and Wang (2006), mention culturally rooted assumptions of the roles of Chinese learners, such as the expectation that due to the influence of Confucianism, they tend to passively receive knowledge. However, this tendency was not evident in the observations conducted in the present study.

\section{4) Teaching and learning activities}

The participants generally believed that there were differences between the teaching and learning activities conducted in China and Australia. Instructional activities in Chinese classrooms lean towards drills, grammatical knowledge, and exercises, while language teaching in Australia emphasizes the balance between four macro-skills, and focuses on the use of language, rather than its mere rules and forms. Below are the excerpts of a few participants: 


\section{Excerpt 5}

It was very boring to attend English classes in China because the instructional activities emphasized grammatical explanations and exercises. (Alicia)

\section{Excerpt 6}

In writing classes (in China), we were required to imitate writing samples and recite useful expressions. I felt bored and demotivated. (Betty)

\section{Excerpt 7}

My overall English capabilities have improved in Australia. I've benefited a lot from the presentations and group discussions, as well as from writing. (Chan)

As can be seen from these transcripts, the participants had lower motivation about traditional grammar instruction and rote-learning styles; Conversely, they showed favorable attitudes toward Australian teaching pedagogy, and had greatly benefited from the comprehensive training in their English skills at the ELC.

5) Assessment

When asked to comment on the forms of assessment in use at the ELC, the participants considered that the tests they did were an all-round assessment of students' English proficiency. For example, Danna said:

Excerpt 8

The exams we take in China focus on grammar, reading, and writing more than speaking and listening. At the $E L C$, however all four macro-skills are given proper consideration and are assessed.

Monica was very enthusiastic and excited about the oral exam, especially the preparation process:

\section{Excerpt 9}

I like problem-solving task in the final exam. This activity is to test how you solve a problem in an oral conversation with a partner. Because we had no idea about who our partner would be in the exam, we had to practice speaking with different classmates. I was very excited about the process, because it trains me how to cooperate with partners and solve problems step by step.

Clearly, this participant was very positive about the oral exams she took, and viewed the preparation process as a way to develop her teamwork and problem-solving skills.

6) Connections between the two learning experiences

The participants generally stated that their prior learning experiences both facilitated and impeded their language learning in Australia. In terms of facilitation, most thought that the grammatical knowledge and vocabulary acquired in China were very helpful for their current studies in Australia. As to the negative influence, they attributed their poor communication skills to the unequal balance between the four-macro skills of languages and the form-based classroom activities and exams. Below are the participants' transcripts.

\section{Excerpt 10}

Because listening, speaking, and writing are not properly trained [in China], my oral and written communication skills are comparatively weak and need to be improved. (Betty)

\section{Excerpt 11}

Although learning by rote, such as repetitive drills and recitation, has some negative impacts on my studies, it has enabled me to grasp plenty of new words and grammar rules, which is very useful for reading comprehension and oral expressions. (Lily)

As can be seen from the data, the participant regarded memorization and recitation as a useful strategy to accumulate words and study grammar rules, although they revealed negative attitudes toward the rote-learning style. Chan (1999) contends that memorization should not be equated with rote learning style. Ho et al. (1999) also maintain that memorization based on understanding is an effective learning approach. It could be argued that memorization and understanding were intertwined through their learning to achieve better results.

\subsubsection{Chinese Learners' Attitudes Toward CLT}

When asked about the activities that they preferred and deemed most useful at the ELC, all of the participants mentioned communicative activities, such as group discussions, oral presentations, and excursions, because these activities helped them to improve communicative competence and problem-solving skills, and become acquainted with foreign accents and cultures. The excerpts below reveal such feelings and views: 


\section{Excerpt 12}

I like to take short excursions as they provided me with opportunities to explore local history and culture, as well as communicate widely with local people. (Ying)

\section{Excerpt 13}

I enjoy group discussions as I could get to know some non-Chinese students in our class, and learn about their cultures and languages. (Chan)

While appreciating the benefits gained from communicative activities, two participants questioned the effectiveness of the group discussions. Alicia tended to evaluate group work more negatively, identifying drawbacks such as digressions in discussions, uncooperative partners, and people using their mother tongue to express ideas, although she acknowledged that she did reap some direct benefit from it.

\section{Excerpt 14}

The group discussions have clarified my confusion. However, we can easily go off topic as the majority of my classmates are Chinese. Due to limited vocabulary, we sometimes had to use our mother tongue.

Danna also raised similar concerns, although she was positive about the group work as a whole. She believed that a system should be established to ensure the effectiveness of group discussions.

\section{Excerpt 15}

Group discussions need to operate in such a way that everyone does their fair share, and contributes to the discussion. If one person is selected to do the group presentation, others may passively join in the activity.

These concerns indicated that not all of the participants held uniform views about collaborative work.

\subsubsection{Chinese Learners' Attitudes Toward Grammar Activities}

The data suggested that the participants revealed diverging beliefs about grammar activities. Six showed favorable attitudes toward the grammar instruction they received at the ELC; two expressed less interest, but acknowledged that it was an integral part of learning English; while the remaining two students simply found it boring.

The excerpts below outline the participants' feelings and views:

1) A preference for grammar learning through games:

Excerpt 16

I enjoy learning grammar by playing games, which I find to be an effective way of memorizing new words and learning grammar rules. (Lily)

Apparently, games, to some extent, have resulted in improved efficacy in Lily's vocabulary acquisition. She has drawn much benefit from them.

\section{Excerpt 17}

I enjoy learning grammar through games, because it has greatly boosted my enthusiasm and motivation... (Ying)

Ying's response revealed her belief that grammar instruction in communicative activities had aroused her motivation and interest.

It seems that an integration of FFI and communicative activities has a greater effect on teaching and learning outcomes than grammar instruction in isolation.

2) A preference for grammar learning in other modalities:

Some participants stated that grammar instruction in combination with writing constituted an effective approach to relate grammatical knowledge to academic writing. In this way, they learned how to write more argumentatively and persuasively. For example, Cassy commented:

Excerpt 18

I prefer grammar to be taught together with writing, because in this way I learned how to use conjunctions properly to make sentences more coherent, and how to use formal language to make writing more academic.

The results suggested that integrating grammar instruction with writing is likely to assist learners in absorbing theoretical knowledge and using grammar concepts more easily. Hence, the participants' positive attitudes echo Imai's (2007) findings, that learners are favorable about grammar instruction via different modalities. 
3) Less interest in learning grammar

Two participants were less interested in grammatical knowledge, but acknowledged its importance in language study.

\section{Excerpt 19}

Compared with communicative activities, I have less interest in grammar. However, it's necessary to learn it; after all, grammar is the foundation of communication. (Cassy)

This neutral attitude revealed that, although these few participants had less motivation to study grammar, they recognized its great value and importance.

4) A lack of interest in learning grammar

Two participants said that they disliked grammar due to its theoretical principles and individual learning difficulties.

\section{Excerpt 20}

I don't like grammar exercises because they're very boring. I'm also very bad at them. (Chan)

This indicated that the personal feelings toward grammar were dictated by one's grammatical knowledge, academic performance, and personal preferences. It seems that individual factors related to English proficiency play an important role in determining learners' attitudes to grammar.

In general, with increasing acculturation, the participants in this study tended to follow the rules of mainstream culture, and gradually became receptive to the cultural values and teaching philosophies of their new academic environment. Being aware of the pressing need to survive in an English-speaking country, they showed highly positive attitudes about communicative approaches and exhibited a particular interest in and motivation toward Western learning styles. Although the participants did not value grammatical knowledge as much as communicative activities, they generally acknowledged its benefits for their current learning, and mostly favoured grammar instruction embedded in communicative practice (such as games and the integration of grammar and academic writing). Hence, a holistic approach, developmental perspective, and culturally sensitive stance may be needed to understand students' dynamic changes of perceptions, as well as their prior learning and literacy experiences.

\subsection{Research Question 2: What Are Chinese Learners' Perceived English Learning Difficulties in Australia?}

Although the participants believed that the English training program was beneficial, many of them considered it very challenging. Consistent with previous studies (Khawaja \& Stallman, 2011; Robertson et al., 2000; Zhang \& $\mathrm{Mi}, 2010$ ), the issues raised mainly related to academic writing, grammar use in the context, oral communication, understanding the Australian accent, and autonomy. Writing was seemingly the most difficult task. Nine participants criticized their own limited English proficiency and written language skills. Speaking and listening were considered less difficult, being mentioned six and four times, respectively, in the responses. Reading seemed to be the least challenging of the four linguistic macro-skills. Only one student raised issues with reading. The results are congruent with Zhang and Mi (2010), who identified that reading does not seem to be a major issue for L2 Chinese learners, but writing does. Below are the major findings.

\subsubsection{Difficulties in Academic Writing}

Coming from a culture that has different discourse patterns, the participants generally found it challenging to learn Australian discourse conventions. Most reported limited knowledge about how to vary the use of language according to the register (e.g. formal and informal language).

For example, Lily commented:

\section{Excerpt 21}

I don't know how to differentiate subjective words from objective ones. I'm unclear about how to avoid subjectivity in my writing.

Peggy once majored in traditional Chinese dramatic literature at a Chinese university. She voiced an original view regarding writing:

\section{Excerpt 22}

The Chinese language emphasizes semantic connections, while English focuses on syntactic devices. When writing in English, I can feel that my thinking and expressions are influenced by my first language. 
Clearly, cross-linguistic influences reflected in the differences in textual syntax and style is another major concern for L2 Chinese students.

\subsubsection{Difficulties in Communication}

Because ELT in China focuses on grammar and academic literacy skills, the participants generally reported that their communicative competence was weak and inadequate, in particular their speaking and listening skills. They tended to attach importance to word form and accuracy, rather than its meaning and fluency.

For example, Monica commented:

Excerpt 23

Initially, I paid great attention to word form and accuracy [when speaking English]. This undoubtedly slowed down my speech and limited its fluency.

Janice noted that her lack of knowledge about the cultural background of Australia hindered her comprehension and interpretation:

Excerpt 24

Due to my insufficient knowledge of foreign cultural backgrounds, I found it difficult to understand the discourse in conversations and movies.

\subsubsection{Difficulties With Independent Learning}

Influenced by the didactic and teacher-centered approach, the participants generally found it challenging to independently seek knowledge in Australia, where originality and creativity are highly encouraged in learning contexts. Some of these difficulties related to the transition from a passive recipient to an active and autonomous learner.

For example, Betty commented:

\section{Excerpt 25}

In Australia, we don't just reproduce what we have learned, but have to research on our own. To complete an assignment, we need to engage in reading and researching. As I've been used to being spoon-fed, it takes some time to change and improve.

Betty's comments reflected part of the learners' current learning state. Although desiring to change learning habits, they still found it difficult to go beyond their "comfort zone".

No one is a "blank slate" on their first day when starting a new course. All learners may be affected by what they have been taught or learned before (Sawir, 2005). As reflected in the data, issues with grammar use and difficulties with assignments are partly related to the participants' prior teaching and learning styles. In addition, cultural differences in writing pose another difficulty to Chinese international students; the originality and creativity stressed in the Western tradition may collide with the imitative cultural practices valued in the Chinese context. Research into ESL writing has found that there are marked differences between cultures in terms of rhetorical conventions, cultural schemata, and writing perspectives or expectations (Hyland, 2003). Conceivably, to improve one's L2 literacy skills is a daunting task, and may take years of training to develop.

Biggs (1997) argues that identifying problems is insufficient; it is important to move beyond problems and gaps to seek strategies that can be adopted by students. In a sense, identifying the underlying causes of problems will shed light on the development of strategies aimed at improved teaching and learning outcomes. Therefore, both students and staff need to work together to develop "an appropriate teaching and learning environment which is context related, inclusive of and accepting of intercultural difference" (Robertson et al., 2000, p. 101).

\section{Conclusion and Implications}

This paper has examined how Chinese ESL learners perceive ELT in the Australian context and the learning difficulties they have encountered in their English studies. According to the findings, participants gradually became able to follow the rules of mainstream culture and became receptive to the cultural values and teaching philosophies of their new academic environment. Being aware of the pressing need to survive in an English-speaking country, they showed highly positive attitudes about CLT, and mostly favored grammar instruction within communicative practice. Also, the results reveal that the participants touched mostly on challenges related to academic writing, grammar use, communication skills and autonomous learning. To some extent, their learning difficulties were affected by the prior teaching and learning styles to which they had been exposed, as well as cultural differences. 
In addition, the study highlights several implications:

First, given that ESL learners favor the integration of grammar instruction within communicative practice, it is very important to combine both implicit and explicit grammar instructions in language teaching and learning. This would equally develop learners' communicative and grammatical competence, as well as sustain their interest and motivation.

Second, the research findings reveal that particular cultures of learning and contextual factors to some extent shape people's perceptions and socio-cultural values. Being in a transitional and rebirth process from passive learning to active participation, some of the participants possibly have views that are incongruous with the host teachers' methodological beliefs, such as the value of the participatory approach and group work. However, if teachers are more aware of learners' past learning experiences (Kumaravadivelu, 1991), they might engage in more effective interventions and facilitate the desired learning outcomes. For this reason, it is suggested that teachers should perform "context analysis" before starting to teach so that they are better positioned to decide how to proceed and develop their own approach.

In addition, considering learners' needs and individual differences, "cultural synergy" (Cortazzi \& Jin, 1996, p. 317), i.e. negotiation between teachers and students regarding a possible solution, is needed. This would bridge the gap between methodological beliefs and students' preferences, and enable two opposing opinions to be accommodated (Parris-Kidd \& Barnett, 2011).

Third, since participants' learning difficulties are partly influenced by their prior exposure to traditional teaching methods and learning styles, it could be argued that necessary interventions should be considered in their home country (China) and the country where they are currently studying (Australia). Given the situational constraints in mainland China, a hybrid model, such as blending CLT with traditional Chinese approaches, is highly recommended in Chinese classrooms. In addition, Australian host institutions would do well to learn more about Chinese students' learning difficulties, and their prior learning experiences. This would enable host instructors to establish what interventions are needed at which stages and to assist learners in developing their own learning strategies in the academic adaptation.

\section{Acknowledgments}

I would like to give special thanks to the research participants and English Language Centre of Macquarie University for their enthusiastic involvement and great support. I also express my deep gratitude to the staff members of the department, who have supported me at different stages of my research.

\section{References}

Ashton-Hay, S., Wignell, P., \& Evans, K. (2016). International student transitioning experiences: Student voice. Journal of Academic Language and Learning, 10(1), A1-A19.

Atkinson, D. (1997). A critical approach to critical thinking in TESOL. TESOL Quarterly, 31(1), 71-94. https://doi.org/10.2307/3587975

Barkhuizen, G. P. (1998). Discovering learners' perceptions of ESL classroom teaching/learning activities in South African context. TESOL Quarterly, 32(1), 85-108. https://doi.org/10.2307/3587903

Biggs, J. (1997). Teaching across and within cultures: the issue of international students. In R. Murray-Harvey, \& H. S. Silins (Eds.), Learning and teaching in higher education: Advancing international perspectives. Proceedings of the Higher Education Research and Development Society Conference (pp. 1-22). Adelaide, Australia: Higher Education Research and Development Society of Australasia (HERDSA).

Chan, S. (1999). The Chinese learner - a question of style. Education \& Training, 41(6/7), 294-304. https://doi.org/10.1108/00400919910285345

Chinese Ministry of Education. (2018). 2017 sees increase in number of Chinese students studying abroad and returning after overseas studies. Retrieved from http://en.moe.gov.cn/News/Top_News/201804/t20180404_ 332354.html

Cortazzi, M., \& Jin, L.X. (1996). Cultures of learning: Language classrooms in China. In H. Coleman (Ed.), Society and the language classroom (pp. 169-206). Cambridge: Cambridge University Press.

Durrani, H. (2016). Attitudes of undergraduates towards grammar translation method and communicative language teaching in EFL context: A case study of SBK Women's University Quetta, Pakistan. Advances in Language and Literary Studies, 7(4), 167-172. https://doi.org/10.7575/aiac.alls.v.7n.4p.167

Floyd, C. B. (2015). Closing the gap: International student pathways, academic performance and academic 
acculturation. Journal of Academic Language and Learning, 9(2), A2-A18.

Grundmeyer, T. A. (2012). A qualitative study of the perceptions of first-year college students regarding technology and college readiness (Doctoral dissertation, Iowa State University, USA). Retrieved from http://lib.dr.iastate.edu/etd/12599/

Gu, Q., \& Maley, A. (2008). Changing places: A study of Chinese students in the UK. Language and Intercultural Communication, 8(4), 224-245. https://doi.org/10.1080/14708470802303025

Hellsten, M. (2002). Students in transition: needs and experiences of international students in Australia. Paper presented at the $16^{\text {th }}$ Australian International Education Conference, Hobart, Tasmania.

Ho, I., Salili, F., Biggs, J., \& Hau, K. T. (1999). The relationship among causal attributions, learning strategies and level of achievement: A Hong Kong case study. Asia Pacific Journal of Education, 19(1), 44-58. https://doi.org/10.1080/0218879990190105

Horwitz, E. K. (1999). Cultural and situational influences on foreign language learners' beliefs about language learning: A review of BALLI studies. System, 27(4), 557-576. https://doi.org/10.1016/S0346251X(99)00050-0

$\mathrm{Hu}, \mathrm{G} . \mathrm{W}$. (2002). Potential cultural resistance to pedagogical imports: The case of communicative language teaching in China. Language, Culture and Curriculum, 15(2), 93-105. https://doi.org/10.1080/079083 10208666636

Hyland, K. (2003). Second language writing. Cambridge, UK: Cambridge University Press. https://doi.org/10. 1017/CBO9780511667251

Ikpia, V. I. (2001). The attitudes and perceptions of adult English as a second language students toward explicit grammar instruction (Unpublished doctoral thesis), New Mexico State University, USA.

Imai, J. (2007). Learner beliefs about isolated and integrated form-focused instruction: Japanese high-school learners of English as a second language in the United States (Unpublished doctoral thesis), University of Toronto, Canada.

Incecay, G., \& Incecay, V. (2009). Turkish university students' perceptions of communicative and non-communicative activities in EFL classroom. Procedia Social and Behavioral Sciences, 1(1), 618-622. https://doi.org/10.1016/j.sbspro.2009.01.110

Kavoshian, S., Medadian, G., \& Lorzadeh, M. (2013). Iranian language learners' conceptions of the ideal English lesson: Form-focused or communicative. Theory and Practice in Language Studies, 3(8), 1352-1359. https://doi.org/10.4304/tpls.3.8.1352-1359

Khawaja, N. G., \& Stallman, H. M. (2011). Understanding the coping strategies of international students: A qualitative approach. Australian Journal of Guidance and Counselling, 21, 203-224. https://doi.org/10. 1375/ajgc.21.2.203

Koziol, M. (2018). Chinese student numbers 'fairly modest' with room to grow, says minister. Retrieved from https://www.smh.com.au/politics/federal/chinese-student-numbers-fairly-modest-with-room-to-grow-saysminister-20180302-p4z2gr.html

Krashen, S. D., \& Terrell, T. D. (1983). The natural approach: Language acquisition in the classroom. Hayward, CA: Alemany Press.

Kumaravadivelu, B. (1991). Language-learning tasks: Teacher intention and learner interpretation. ELT Journal, 45(2), 98-107. https://doi.org/10.1093/elt/45.2.98

Lee, B., Farruggia, S. P., \& Brown, G. T. L. (2013). Academic difficulties encountered by East Asian international university students in New Zealand. Higher Education Research \& Development, 32(6), 915-931. https://doi.org/10.1080/07294360.2013.806444

Merleau-ponty, M. (2013). Phenomenology of perception. UK: Taylor and Francis.

Mitsui, N. (2009). Accommodating CLT in Korean EFL classrooms (Unpublished master thesis). Gonzaga University, Washington, USA.

Panksepp, J. (1998). Affective neuroscience: The foundations of human and animal emotions. New York: Oxford University Press.

Parris-Kidd, H., \& Barnett, J. (2011). Cultures of learning and student participation: Chinese learners in a multicultural English class in Australia. In L. X. Jin, \& M. Cortazzi (Eds.) Researching Chinese learners- 
skills, perceptions and intercultural adaptations (pp. 169-187). UK: Palgrave Macmillan. https://doi.org/10.1057/9780230299481_8

Robertson, M., Line, M., Jones, S., \& Thomas, S. (2000). International students, learning environments and perceptions: A case study using the Delphi technique. Higher Education Research and Development, 19(1), 89-102. https://doi.org/10.1080/07294360050020499

Rossman, G. B., \& Rallis, S. F. (2003). Learning in the field: An introduction to qualitative research (2nd ed.). Thousand Oaks, CA: Sage.

Saito, H., \& Ebsworth, M. E. (2004). Seeing English language teaching and learning through the eyes of Japanese EFL and ESL students. Foreign Language Annals, 37(1), 111-124. https://doi.org/10.1111/ j.1944-9720.2004.tb02178.x

Sawir, E. (2005). Language difficulties of international students in Australia: The effects of prior learning experience. International Education Journal, 6(5), 567- 580.

Schmidt, R. (1995). Attention and awareness in foreign language learning. Honolulu, HI: Second Language Teaching \& Curriculum Centre.

Smith, A. D. (2002). The problem of perception. Cambridge, MA: Harvard University Press.

Wang, T. (2006). Understanding Chinese culture and learning. Paper presented at the AARE Annual Conference, Adelaide. Retrieved from https://www.aare.edu.au/data/publications/2006/wan06122.pdf

Wolfe, J., Kluender, K., \& Dennis, L. (2009). Sensation and perception. Sunderland, MA: Sinauer Associates.

Wong, J. K. (2004). Are the learning styles of Asian internationals culturally or contextually based? International Education Journal, 4(4), 154-166.

Yu, B. H., \& Shen, H. Z. (2012). Predicting roles of linguistic confidence, integrative motivation and second language proficiency on cross-cultural adaptation. International Journal of Intercultural Relations, 36(1), 72-82. https://doi.org/10.1016/j.ijintrel.2010.12.002

Zeng, M. (2004). The role of grammatical instruction within communicative language teaching among Chinese ESL students (Master's thesis, University of Windsor, Canada). Available from ProQuest Dissertations Publishing).

Zhang, Y. Y., \& M, Y. N. (2010). Another look at the language difficulties of international students. Journal of Studies in International Education, 14(4), 371-388. https://doi.org/10.1177/1028315309336031

\section{Appendix A}

\section{Participant's demographic information}

Name:

Age:

Gender:

Phone:

Email:

Highest degree completed:

Degree applying for:

IELTS test score:

Hometown in China:

Residence in Australia:

English proficiency in the class:

Good fair poor

\section{Appendix B}

\section{Interview questions}

Part 1 Students' perceptions of English language teaching and learning in Australia 
1.1 Perception in relation to the students' impressions:

From what you see, hear, and do at the ELC, can you tell me about your general impressions of English classes? How do you view these classes in terms of teacher/learner roles, teacher behavior, teaching materials, teaching and learning activities, the learning environment, and assessments?

1.2 Perceptions in relation to the students' interpretations of representations:

1) Given your English learning experience in China, what did you expect to observe in the Australian English language classes? Tell me about your experiences of learning English in China and Australia (ELC). What do you feel about the way English is taught and learned in China, compared with your experiences in Australia?

2) Tell me about the activities at the ELC that you find most useful in helping you to improve your communication skills (e.g. group discussion, pair work, oral presentations)? What do you think about learning to communicate with your teacher and classmates?

1.3 Perceptions in relation to the students' affective experiences:

1) Could you please talk about the teaching and learning activities that you enjoy most (e.g. group discussions, grammar exercises, or presentations)?

2) Could you please talk about the teaching and learning activities that you dislike or that you feel uncomfortable with (e.g. group discussions, grammar exercises, and presentations)?

\section{Part 2 Students' learning difficulties at the ELC}

1) In your responses to the above questions, you referred to the following differences between the two contexts (China and Australia), in terms of English language teaching and learning.
a. $\quad$ AAAAA
b. BBBBB
c. $\mathrm{CCCCC}$

How do these differences affect your English language learning in Australia? Can you elaborate on the difficulties you have faced as a result of these differences?

2) Do you think your prior learning experiences (e.g. the focus of classroom teaching/ exams/ assignments/ class sizes/ the physical layout of classroom/ teacher behavior) facilitate or impede your language learning in Australia?

Which aspects of learning English at the ELC do you find most helpful and which aspects do you find less helpful or difficult (e.g. reading, speaking, listening, and writing)?

\section{Copyrights}

Copyright for this article is retained by the author(s), with first publication rights granted to the journal.

This is an open-access article distributed under the terms and conditions of the Creative Commons Attribution license (http://creativecommons.org/licenses/by/4.0/). 